\title{
Annus Horribilis, Annus Mirabilis
}

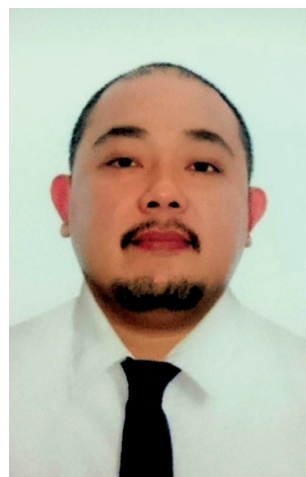

We all started 2020 with high hopes and expectations, brimming with dreams and full of plans for what was supposedly a lucky year. But 2020 is an annus horribilis, a year that this generation will not forget, as we all came face to face with an outbreak of global proportions. That a submicroscopic assembly of protein and nucleic acid can wreak so much havoc to our supposedly modernized lives, bringing economies and health systems down on their knees, reiterates how fragile and ill-prepared the world is.

I welcome all of you to another issue of the Philippine Journal of Pathology, our second for 2020. We feature this time two articles related to the COVID-19 pandemic: the first, a review of the challenges on contamination for SARS-COV-2 molecular laboratories which should be recognized and addressed to ensure quality laboratory results; and the second, the pragmatic study on pooled testing of the Philippine Society of Pathologists, which now forms a solid basis for the recent policy issued by the Department of Health. Rounding up this issue are 2 interesting case reports on a primary rhabdomyosarcoma in the brain as well as a metaplastic carcinoma post breast augmentation with silicone, and a meta-analysis on the utility of mean platelet volume for diagnosis of acute myocardial infarction.

I am very pleased also to share the editorial byline for this issue with Dr. Raymundo Lo, one of PJP's esteemed editorial board members, a respected columnist tackling issues on laboratory medicine, a member of the DOH COVID Laboratory Experts

Panel (CLEP) representing the Philippine Society of Pathologists, and the principal investigator of the pooled testing study, as he traces the journey from germination to fruition of the study amid the changing landscape of clinical pathology in the country. It is my hope that the Society and its members will be inspired by this concrete example of research being translated to policy and practice. Ultimately, this is what research is meant to be for.

In 1905, Albert Einstein published four studies in the scientific journal Annals of Physics. These articles are now known collectively as the Annus mirabilis papers - considered as major contributions to the foundation of modern physics, revolutionizing the concepts of time, space, mass, and energy, and which included his most famous formula, $E=m c^{2}$. Remarkably, all were published in a single "miracle year." While these articles were groundbreaking and continues to break ground up to the present, our collective efforts as pathologists in this side of the globe to battle the COVID-19 pandemic with laboratory science, is historic.

2020 is a year that has brought on the worst, and yet brought out the best in us: an annus horribiliswhat I have described in the last issue as the Year of the Filipino Pathologist_that is nothing short of mirabilis.

\section{Amado O. Tandoc III, MD, FPSP}

Editor-in-Chief

https://doi.org/10.21141/PJP.2020.14 